\title{
A NOMEAÇÃO NO TRACTATUS DE WITTGENSTEIN
}

\author{
$\underline{\text { Juan Erlle Cunha de Oliveira }}{ }^{1}$; Wagner Teles de Oliveira ${ }^{2}$ \\ 1. Bolsista FAPESB/PIBIC, Graduando em Filosofia, Universidade Estadual de Feira de Santana, e-mail: \\ juan.erlle@gmail.com \\ 2. Orientador, Departamento de Ciências Humanas e Filosofia, Universidade Estadual de Feira de Santana, e-mail: \\ woteles@gmail.com
}

PALAVRAS-CHAVE: Wittgenstein; nomeação; linguagem.

\section{INTRODUÇÃO}

O que está em jogo na exigência de significado do nome é o postulado da figuração da linguagem frente ao mundo. Não havendo objeto, não há como estabelecer figuração; não havendo nome, não há proposição. Ora, se os objetos são simples e fixos (Cf. 2.02), inalteráveis em sub specie aeterni, mas variável apenas pelas possibilidades dos seus arranjos com outros, os seus nomes não podem ser definidos (Cf. 3.261; PINTO, 1998, p. 185), caso contrário o valor de verdade de uma proposição dependeria previamente da definição do nome que emprega, isto é, de outra proposição e assim ad infinitum, desmoronando a tese isomorfista do Tractatus. O nome também é simples e fixo (PINTO, 1998, p. 197), mas articulados com os elementos da proposição/figuração tal qual os objetos nos estados de coisas, como aponta o aforismo 3.21. Ademais, da "inefabilidade da existência" do objeto (Cf. Hintikka \& Hintikka, 1994), isto é, que seja impossível exprimir a sua existência - "Não podemos pensar em nenhum objeto fora da possibilidade de sua ligação com outros" (Cf. 2.0121) - tem-se como contraparte a indefinibilidade do nome. Assim, o nome não é independente da proposição de que é elemento constituinte. Notemos que no início do aforismo 3.221, Wittgenstein diz: "Os objetos, só posso nomeá-los". O que se entende pelo verbo "posso" e a ação de nomear ("nomeá-los")? O rubicão deste trabalho consiste no fato de que um nome não está inscrito na natureza do objeto, tampouco é expediente da lógica selecionar qual nome deve nomear qual objeto, como atesta o próprio autor. Apenas se exige que uma correspondência deve haver. Neste sentido, pretendemos investigar a possível atuação de um sujeito transcendental capaz de conferir um nome a um objeto determinado e o princípio do contexto, como põe o aforismo 3.3. Não obstante, a tese do sujeito transcendental não implica em verter a nomeação em linguagem, posto que habita fora dos limites do mundo, no inefável. É por isso que alguns comentadores cotejam esse "segredo" do Tractatus a ponto de considerar a necessidade de um Deus. (Cf. SALLES, 2006a). É preciso salientar que esse problema não é suficientemente resolvido pelo princípio do contexto (Cf. 3.3), pois, embora a própria proposição indique a que objeto um nome se refere, ainda não explica quem ou $o$ quê dá um nome $x$ a um objeto $\mathrm{x}^{`}$. A pertinência desse tema não se esgota no Tractatus. Trata-se de uma questão que tem desdobramentos importantes para a compreensão do sentido da obra futura de Wittgenstein, como as Investigações Filosóficas, na ostensão linguística, o que fundamenta a pertinência desse plano de trabalho.

\section{MATERIAL E MÉTODOS OU METODOLOGIA (ou equivalente)}


O presente estudo far-se-á a partir de uma perspectiva internalista do Tractatus. Assim, a investigação privilegiará, no primeiro momento, a leitura e releitura sistemáticas e do fichamento da obra a partir dos principais conceitos da pesquisa, aprofundando no estudo sobre a teoria pictórica e nomeação.

\section{RESULTADOS E/OU DISCUSSÃO (ou Análise e discussão dos resultados)}

No Tractatus, a articulação sintática entre os elementos da figuração é, ponto a ponto, uma refração da coordenação lógica entre objetos em seus estados de coisas. $\mathrm{O}$ estatuto da nomeação - reflexão que envolve, grosso modo, a vinculação do nome ao objeto na relação afigurante - importa a esta tarefa porque se trata, antes de mais nada, de uma exigência técnica do Tractatus que, sem a qual, não haveria contato entre mundo e linguagem, tornando impossível que algo seja dito. Ser um objeto significado de um nome é evitar que o sentido de uma proposição dependa de outra proposição, regredindo assim ao infinito (2.0211). Então o postulado do objeto como substância simples e fixa $(2.02,2.0271)$, sendo variável apenas a configuração de seus estados de coisas, é garantia de que a linguagem seja capaz de "traçar uma figuração do mundo", não importando se falsa ou verdadeiramente. A consequência disso, constituindo uma das principais inovações de Wittgenstein, é que uma proposição, ainda que falsa, isto é, que não representa uma ocorrência efetiva no mundo, é também imbuída de sentido ou seja, do ponto de vista lógico tal proposição poderia perfeitamente ocorrer, mas não ser o caso é uma simples questão acidental e não lógica. Tanto a proposição falsa quanto a proposição verdadeira, portanto, são similares no que concerne ao estatuto da nomeação, pois cada qual traz consigo um nome que substitui na proposição o objeto sobre o qual se faz figuração. Isso porque os objetos são fixos, constituem a substância do mundo, e não estão condicionados a qualquer outra coisa, nem a uma subjetiva ou qualquer outra intervenção arbitrária do homem, por exemplo.

Em 4.1272, Wittgenstein diz que não se pode dizer "há objetos": trata-se de um contrassenso; não tem sentido tentar exprimir a existência isoladamente de objetos. Isso porque, para Wittgenstein, o objeto só é pensado dentro de uma configuração. Como diz Margutti Pinto (1998, p.179):

Enquanto se acha essencialmente vinculado ao fato atômico, o objeto dele depende pra existir. O objeto só existe no interior do fato atômico; isoladamente, ele apenas "subsiste" (no nível transcendental).

Assim como o objeto é, isoladamente, inefável, o seu nome tampouco pode ser desmembrado em outra definição (Cf. 3.26) sequer pode ser caracterizado como um nome:

O nome só é nome no contexto de uma proposição. Tomado isoladamente, ele é uma mera abstração sintática, definida pelo papel que pode desempenhar no interior de proposições. (SANTOS, 2008, p. 72)

Isso posto, é então exatamente quando uma figuração é constituída, quando "figuramos os fatos", que a significação do nome é dada. Tal é o princípio do contexto, descrito por Wittgenstein em 3.3: "Só a proposição tem sentido; é só no contexto da proposição que um nome tem significado". Isso quer dizer que os significados dos sinais, os nomes, não são determinados isoladamente em uma etapa prévia à proposição, ao gosto de uma vinculação que se assinala apontando com o dedo: pelo contrário, o objeto é "conhecido" no próprio contexto da proposição (3.263), quando o seu nome 
está articulado com outros nomes, em consonância com os fundamentos da sintaxe lógica. Esse ponto específico do Tractatus estimulou comentadores do filósofo a indagar como ocorre essa vinculação propriamente dita, entre um objeto determinado e o seu nome específico, como um nome é escolhido, arbitrariamente, em detrimento de outros; e se isso não exigiria a atuação de um sujeito transcendental.

\section{CONSIDERAÇÕES FINAIS (ou Conclusão)}

A hipótese de um sujeito transcendental, mobilizada pela perspectiva da nomeação, é enigmático na medida em que o próprio Wittgenstein não tratou de maneira explícita no Tractatus, sendo, portanto, um desses trabalhos de exegese levado a cabo por alguns comentadores. A hipótese nos parece legítima, estimula a curiosidade e nos abre à reflexão, mas ainda carece de maior sustentação que se admita, de forma peremptória, que há no Tractatus a necessidade de um sujeito transcendental - chamamos a atenção para o forte termo necessidade. A razão é a seguinte: é pouco importante se o objeto a que chamamos de livro é representado, numa proposição, pelo nome livro ou qualquer outro; sendo pouco importante, com isso, a atuação de um sujeito transcendental responsável por uma escolha em detrimento de outra. Ou, no melhor das hipóteses, a atuação ou ausência de um sujeito transcendental em nada alteraria a teoria da linguagem de Wittgenstein, sendo, por isso, um algo que não é necessário, talvez até dispensável - e se em Wittgenstein tudo é lógico, ser o sujeito transcendental dispensável é não ter ele qualquer apelo lógico. Ademais, dar essa importância - a necessidade de um sujeito transcendental - é reduzir o papel desempenhado pela teórica pictórica, cuja relação afigurante entre linguagem e mundo faz, logicamente, um nome ser dotado de significado. Mas sabemos que a teoria pictórica de Wittgenstein, que inclui aí a teoria do nome, é bem mais tematizada no Tractatus que a hipótese de um sujeito transcendental atuante.

Por fim, este estudo nos colocou diante dos indiscerníveis, no qual trouxemos aqui o delineamento desse problema. A hipótese do sujeito transcendental pode ser explorada a partir do aforismo 2.02331, que consiste, a nosso ver, em tensionar ainda mais a perspectiva dos defensores dessa tese: se os comentadores perguntam como um nome específico é escolhido, dentre outros nomes possíveis, para nomear um objeto específico, podemos perguntar, trazendo a nossa perspectiva, como um nome nomeia um objeto específico que tem as mesmas formas lógicas de outro, sendo estes, portanto, indiscerníveis. Como pontuamos no relatório, não apresentamos aqui nenhuma resposta, mas essa investigação fará parte da nossa próxima pesquisa. Encontramo-nos, portanto, em uma atitude de suspeito a respeito do sujeito transcendental, que será posto em discussão a partir dos indiscerníveis.

\section{REFERÊNCIAS BIBLIOGRÁFICAS E OUTRAS}

BAKER, G. P. Wittgenstein's Method: Neglected Aspects. Oxford: Blackwell, 2004.

CUTER, João Vergílio. “'P diz p”. In: Cadernos Wittgenstein, n. 1. São Paulo: USP, 2000

CUTER, João Vergílio Gallerani. Subjetividade empírica e transcendental no Tractatus de Wittgenstein. Revista PHILÓSOPHOS. São Paulo, v. 8, n. 1, jun. 2003.

CUTER, João Vergílio Gallerani. Por que o Tractatus necessita de um sujeito transcendental? DoisPontos. Curitiba, v.3, n.1, abr. 2006. 
CUTER, João Vergílio. Gramática e verdade necessária. In: Revista Dois Pontos, vol. 6, n. 2. Curitiba: UFPR, 2009.

GLOCK, Hans-Johann. Dicionário Wittgenstein. Rio de Janeiro: Jorge Zahar, 1998.

GRIFFIN, JAMES. O Atomismo Lógico de Wittgenstein. Trad. Marina Ramos Themudo e Vítor Moura. Portugal: Porto Editora, 1998.

HACKER, P.M.S. Insight and Illusion: Wittgenstein on Philosophy and the Metaphysics of Experience. Oxford: Clarendon Press, 1972.

HINTIKKA, J. Uma investigação sobre Wittgenstein. Campinas: Papirus, 1994.

MONK, Ray. Wittgenstein: o dever do gênio. Trad. Carlos Afonso Malferrari. São Paulo: Companhia das Letras, 1995.

MORENO, Arley. Conhecimento científico do individual e comentários filosóficos uma análise do Tractatus. In: Revista Transformação, vol. 1. Marília: UNESP, 1974.

MORENO, Arley R. Wittgenstein: os labirintos da linguagem: ensaio introdutório. São Paulo: Moderna, 2000.

PEARS, David. As idéias de Wittgenstein. Tradução de Octanny Silveira da Mota e Leônidas Hegenberg. São Paulo: Cultrix, 1971.

PINTO, Paulo Roberto Margutti. Iniciação ao silêncio: análise do Tractatus de Wittgenstein. São Paulo: edições Loyola (coleção Filosofia), 1998.

SALLES, João Carlos. O Retrato do Vermelho e outros ensaios. Salvador: Quarteto, 2016.

SALLES, João Carlos. "Algumas Considerações sobre Deus e Suas Circunstâncias". In: O Retrato do Vermelho e Outros Ensaios. Salvador: Quarteto, 2016a p. 105-120.

SANTOS, Luiz Henrique Lopes dos. "A Essência da Proposição e a Essência do Mundo”. In: Tractatus Logico-Philosophicus, Edusp, São Paulo, 2008.

WITTGENSTEIN, Ludwig. Tractatus LogicoPhilosophicus. 3.ed. 2.reimp. São Paulo. WITTGENSTEIN, Ludwig. Investigações Filosóficas. Petrópolis: Vozes, 1994. 